\title{
The Impact of Microsystems in Shaping Students' Representations of English as Foreign Language: A Case Study on Bir Ali Middle School of Tunisia
}

\author{
Nessim Bouzayani' ${ }^{1}$ Ali Elloumi ${ }^{2}$ \\ ${ }^{1}$ Ecumus Research Unit, University of Tunis, Tunis, Tunisia \\ ${ }^{2}$ Tec Laboratory, Paris Descartes University, Paris, France \\ Email: alielloumi62@gmail.com
}

How to cite this paper: Bouzayani, N., \& Elloumi, A. (2020). The Impact of Microsystems in Shaping Students' Representations of English as Foreign Language: A Case Study on Bir Ali Middle School of Tunisia. Advances in Applied Sociology, 10, 200-218.

https://doi.org/10.4236/aasoci.2020.106013

Received: May 3, 2020

Accepted: June 6, 2020

Published: June 9, 2020

Copyright $\odot 2020$ by author(s) and Scientific Research Publishing Inc. This work is licensed under the Creative Commons Attribution International License (CC BY 4.0).

http://creativecommons.org/licenses/by/4.0/

(c) (i) Open Access

\begin{abstract}
This paper aimed to analyze the effect of Microsystems (family, school, peer group and media) on shaping students' representations of English as foreign language. This case study was a quantitative and qualitative research. It was carried out to establish and to distinguish causality and dependency relationships between examined variables. This study was conducted in a village called Bir Ali in the south of Tunisia. It targeted 70 middle school students aged 12 to 15 years old. To come up with fruitful findings, we resorted to the mixed methodological approach. We used the questionnaire as a quantitative instrument to statically measure the impact of microsystems on shaping students' representations of English. At the same time, we resorted to the interview: the observation and the content analysis as qualitative instruments to collect qualitative data that help us understand well the mechanism of microsystems and their impact on shaping students' representations of English as a foreign language. Results showed that family, school, peer groups and media shaped positive students' representations of English. The majority of students strongly believe that the acquisition of English is a sign of superiority and it helps them communicate better with the rest of the world enabling them to guarantee good jobs in the future. However, students' outcomes in English remain below expectations.
\end{abstract}

\section{Keywords}

Microsystems, Representations, Students, EFL, Interrelationships 


\section{Introduction}

Students' representations of foreign language are basically shaped within a particular context in which different systems link up to orient learners towards particular representations of specific languages (samples: English, French, Spanish). Thus, our research will be based on two main theories. The concept of "representations" was developed by the social psychologist Serge Moscovici (2001) as "an organism of values, ideas and practices having a double function: the first function lies in the way this system establishes an order that enables individuals to position themselves in their material and social world. Secondly, this organism enables individuals to communicate and interact with the members of community by providing them with a code of social exchange" (Moscovici, 2001: p. 3). Therefore, our investigation on students' representations of English language will shed light on students' values, ideas and practices concerning English as a foreign language and as a result this paper will study the way students interact and develop their representations of English.

In addition, a theory model that can support our investigation will be the model of the ecology systems of Urie Bronfenbrenner (1994). In this research paper, we will focus mainly on microsystems. Urie Bronfenbrenner defines microsystems as a "pattern of activities, social roles and interpersonal relations experienced by the developing person in a given face-to-face setting with particular physical, social and symbolic features that permit engagement in a sustained, progressively more complex interaction with the immediate environment. Examples include such settings are family, school, peer group and work place" (Bronfenbrenner, 1994: p. 39). Henceforth, the ultimate aim of our investigation is to study the way the family, the school, the peer group and media shape students' representations of EFL (English as a foreign language).

Few previous studies were conducted about nearly the same topic. In fact, previous studies shed light on students' representations of EFL but not on the impact of microsystems on it. Cano (2015), for instance, worked on social representation of languages among primary education pupils in Catalonia. She developed a qualitative study using a biographic method. Her research resulted in confirming that plurilingual students (aged 7 and 8) do not show dislike for any language. Then, Meneses and Bello (2017) used a mixed methodological approach working on university students and teachers' representations of English accent in Chile. The authors confirmed that "social representations and ideologies found had little to do with the language itself or linguistic components but are closely related to political, economic, social and historical reasons that construct the background of the English language and the use of 'native speakers' in the teaching and learning of English." (Meneses \& Bello, 2017: p. 3). Other related studies were conducted targeting teachers' representations of EFL which seems irrelevant to our topic.

Thus, our research paper is an academic attempt that studies the impact of microsystems on shaping Bir Ali Prep School Students' representations of English in a context of a changing society. However, an essential question arises and 
it needs a solid answer. On one hand, we postulate that microsystems (family, school, peer group and media) have a direct impact on shaping Bir Ali Prep School students' representation of English. On the other hand, these microsystems do not have the same impact on students' representations of English. So, it is essential to ask the following questions. First, how do microsystems shape students' representations of English? Second, which system is more influential on shaping students' representations of English?

To answer the questions mentioned above, we should point the following hypotheses. First the family has a positive impact on students' representations of English. Second, the school positively shapes students' representations of English. Last, the peer group has a negative impact on students' representations of English. Lastly, media shape particular students' representations of English language.

\section{Materials and Methods}

\subsection{Research Strategy}

In this research paper, we opted to conduct mixed methodological approach using different research instruments. In fact, we resorted to the quantitative approach to collect statistical data using the open-ended questionnaire to measure students' representations of English. We also used the qualitative approach to gather as much as possible qualitative data using the semi-structured interview, the content analysis instrument and the observation instrument in order to understand better the give-and-take processes between students and microsystems.

\subsection{Population and Sample}

The sample comes from a three-year longitudinal study (Table 1). It has 679 students who participated in this study. Two schools are located in a socio-economically disadvantaged neighborhood and two in a neighborhood of privileged social class. The pupils answered the questionnaire during the English course. They are mainly girls (52.9\%) aged 13 to 15 (average age: 14.1 years) (see Table 1).

The target population of this research targets Bir Alimiddle school students.

\subsection{Data Collection Strategies}

\subsubsection{The Open-Ended Questionnaire Instrument}

This questionnaire was conducted in 2018 by the researcher who is at the same

Table 1. Distribution of the study population.

\begin{tabular}{ccc}
\hline \multicolumn{3}{c}{ Bir Ali Middle school } \\
\hline Population & 679 & \\
Boys & 320 & $47.1 \%$ \\
Girls & 359 & $52.9 \%$ \\
\hline
\end{tabular}


time an English teacher in Bir Ali Middle School. It was an open-ended questionnaire including questions on the impact of the four microsystems on shaping students' representations of English (family, school, peer group and media). The questionnaire was designed by the researcher when he conducted an investigation about the impact of the bioecology systems on shaping students' representations of EFL. It was an original investigation tool that was written in Arabic to help students understand better the questions that covered the bioecology systems and their impact on students' perceptions towards EFL.

This questionnaire was distributed to a representative random sample $(10 \%$ of the target population) see Table 2. To analyze this questionnaire we used the SPSS version 20 which enabled us to study and analyze data and the different correlations between variables.

\subsubsection{The Focus Group Instrument}

After completing the analysis of the questionnaire mentioned earlier, we found ourselves obliged to ask the following question: what makes students' performance in English low though they exhibit enthusiasm to learn English?; Therefore, we designed a focus group interview to enable students to respond to the two following questions: What motivates you to acquire English? Why your achievement in English is below expectations? In fact, four focus groups were selected each group contains 15 students.

\subsubsection{The Semi-Structured Interview}

In addition to statistical data obtained via the questionnaire, we opted to gather qualitative data that enabled us to understand well the way microsystems intervene to shape students' representations of EFL. We randomly selected 10 students ( 6 females and 4 males) and asked them different questions covering the four microsystems (family, school, peer group and media). Then, to interpret students' responses to these questions we resorted to the content analysis instrument to analyze the recurrent words and phrases to study the manifest and latent messages of students' answers.

\subsection{Data Analysis Strategy}

The topic under scrutiny involves microsystems as a dependent variable which in return includes four sub-variables: the family, the school, the peer group and media. Therefore, our analysis strategy will cover four themes:

The impact of the family on shaping students' representations of English.

$>$ The impact of school on shaping students' representations of English.

Table 2. Questionnaire sample.

\begin{tabular}{ccc}
\hline & Frequencies & Rate \\
\hline Males & 33 & 47.1 \\
Females & 37 & 52.9 \\
Total & 70 & 100.0
\end{tabular}


The impact of peer group on shaping students' representations of English.

The impact of media on shaping students' representations of English.

\section{Results}

\subsection{The Impact of Microsystems on Shaping Students' Representation of English}

Microsystems represent the closest link to students' environment. In fact, the family, the peer group and the school stand as the students' immediate world in which they develop their attitudes, ideas and representations of events and things including EFL

\subsubsection{The Impact of the Family on Shaping Students' Representation of English}

The family is an important primary socializing agent that has a great impact on kids' socialization and on their output behavior. By consequence the family has an impact on shaping students' representations of EFL.

To start with, we asked students if their parents motivate them to learn English. Results will be shown in Chart 1.

Chart 1 shows that a high rate of students' parents (71\%) encourages them to acquire English as a foreign language. Thus, we can declare that the family and more precisely parents represent a positive push to students to better represent English.

Moreover, we tried to investigate the family's role in shaping their kids' representation of English as a foreign language. It seems obvious to assume that the higher parents' educational level is, the higher they motivate their kids to learn English.

The following statistics (Table 3) clearly describe Bir Ali Prep school students' parents' educational level and their role in motivating students to learn English.

Do your parents motivate you to learn English?

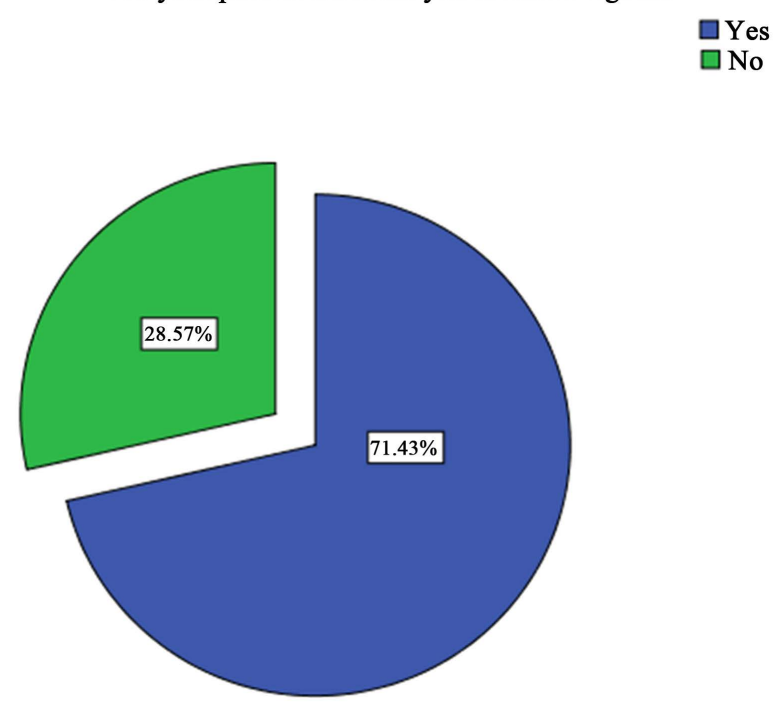

Chart 1. Rate of parents' motivation of their kids. 
In Table 3, the chi-square test results clearly confirm that there is no significance correlation between parents' educational level and their motivation to their kids. Thus, parents and regardless of their educational level have a strong positive representation of English which in return parents will try to transmit this positive representation to their kids.

Then, and to investigate more on the impact of parents on shaping students' representation of English, we asked an open question to students about what their parents say to encourage them to learn English.

To analyze the content of students' answers, we will classify parents' representations of English into 3 categories.

So far, it is obvious that parents in Bir Ali and regardless of their level of education encourage their kids to learn English for many reasons. The first one is to excel at school and have a good mark. The second reason is that English is very important as it is a language of communication. And the third reason emphasizes the role of English in developing students' intellectual and cultural skills.

As a result, the family in Bir Ali has a positive impact on shaping students' representations of English (Table 4).

\subsubsection{The Impact of Peer Group on Shaping Students' Representation of English}

The peer group is a microsystem with dynamic roles and relationships affecting its participants. Unlike the microsystems of the family and school, the peer group is generally unencumbered by adult guidance. The peer group uses informal social mechanisms to develop norms, statuses, alliances, consequences, and feelings about self (Thomson et al., 2002).

In his bioecology systems model, Urie Bronfenbrenner's positions the peer group as an essential microsystem that shapes individuals' behavior throughout their lives. In this research, we will focus on the impact of peer group on shaping students' representations of English.

Table 3. Chi-square test: correlation between parents' educational level and their motivation to their kids.

\begin{tabular}{cccc}
\hline & Value & Ddl & Asymptotic signification (bilateral) \\
\hline Chi-square of Pearson & $1.400^{\mathrm{a}}$ & 3 & 0.706 \\
Number of valid cases & 70 & & \\
\hline
\end{tabular}

Table 4. Parents' representations of English.

\begin{tabular}{ll}
\hline \multicolumn{1}{c}{ Categories } & \multicolumn{1}{c}{ Recurrence of words/expressions } \\
\hline $\begin{array}{l}\text { 1. Important subject at school } \\
\text { Easy subject/important subject/important in the } \\
\text { baccalaureate exam/subject like others/get good mark } \\
\text { in English }\end{array}$ \\
$\begin{array}{l}\text { International language/enables communication } \\
\text { with others/ enables communication with the } \\
\text { world/facilitates communication with societies }\end{array}$ \\
$\begin{array}{l}\text { 3. Language that develops intellectual } \\
\text { and cultural skills }\end{array}$ & $\begin{array}{l}\text { Helps in educational and professional life/open } \\
\text { the doors to travel abroad/understand the world/ }\end{array}$ \\
\hline
\end{tabular}


During my teaching period (Now 11 years) in Bir Ali Prep school, I have witnessed the great impact of peer group on shaping negative representations towards school (Bouzayani, 2018). However, students' inter-influence and the take-and-give process may affect students' representations of English. In fact, students spend much time with their peers exchanging influence and representations of events, people, ideas and objects. As far as English language is concerned, we asked students in the questionnaire if they use English when they communicate with their peers.

Chart 2 reveals the rate of students who use English items when they communicate with each other.

Chart 2 shows that $70 \%$ of the samples sometimes use English to communicate with each other. This high rate proves that students in Bir Ali show no resistance to communicate in English with their peers. Thus, peers will embark on an imitative behavior and will exchange words and expressions using English. In fact, I have observed that many of my students interact with each other using some English items as sign of prestige and showing off.

The following observation grid will clarify better my claims (Table 5).

This grid describes well the students' relationship to English. It provides us with data revealing the students' strong attach to English (Table 5).

Do you sometimes communicate with your peers using English?

$$
\begin{aligned}
& \square \text { Yes } \\
& \square \text { No }
\end{aligned}
$$

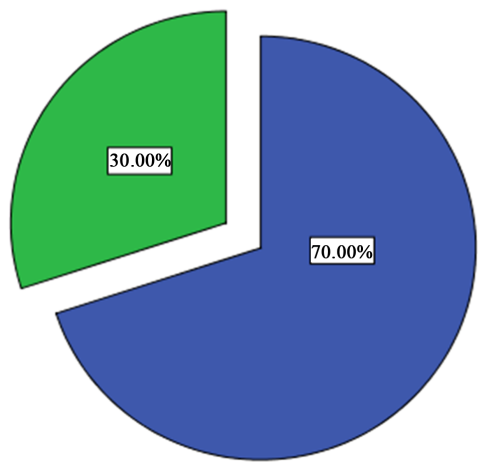

Chart 2. Rate of students who use English to communicate with their peers.

Table 5. The observation grid.

\begin{tabular}{|c|c|}
\hline Observations & Behavior/utterances \\
\hline Outside classroom & $\begin{array}{l}\text { - } \quad \text { Students especially } 7^{\text {th }} \text { formers hurry to line up in front the } \\
\text { English classroom waiting for the teacher even during the breaks } \\
\text { - All students even low achievers try to greet their teachers in } \\
\text { English using "Hi sir/madam", "How are you?". }\end{array}$ \\
\hline Inside classroom & $\begin{array}{l}\text { - Students started using English in their writings on the desks } \\
\text { and on walls. } \\
\text { - } \quad \text { Students wrote English song lyrics on boards, on desks and on walls. } \\
\text { - } \quad \text { Students often say "we love English. We want to acquire it. } \\
\text { We understand in class. But we can't perform well in the test". }\end{array}$ \\
\hline
\end{tabular}


Moreover, students use words such as "OK", "Yes", "Good" and "Nice" and "Of course" inserted in Arabic utterances in their daily interactions. Some high achievers try to insult their peers using English lexis: I heard utterances such as "You are stupid" and "go to hell".

When I asked a group of students (in a focus group interview) about the reason behind their use of some English items, they answered agreeing on that English is "The language of the epoch". They also added that "When we use English, we feel superior" and it is a way to show that we are "intellectual.

The peer group as an agent of socialization in Bronfenbrenner's microsystems has a great impact on shaping a positive students' representation of English. This reality is proven when we have a look at some desks on which students expressed their feelings and emotions in English writing words and expressions such as "love" and " $S+A=$ Love forever" and " $F+H=$ big love."

Students started ignoring the use of French to express their emotions or to declare love to each other.

To answer a question about the reason behind writing some English words on desks or on classrooms walls, students responded spontaneously.

We will analyze their reactions in Table 6 using the content analysis technique. This technique allows us to study three categories (who, whom, why) and to examine the manifest and the latent meaning of students' answers.

The script of two students' answers:

Omaima ( $8^{\text {th }}$ form student) said:

"Perhaps because they want to express their feelings using many languages and may be because English words seem to be more prestigious and superior to the Arabic language"

Yosra ( $9^{\text {th }}$ form student) said:

Table 6. Content analysis of students' responses to the interview.

\begin{tabular}{|c|c|c|c|}
\hline Categories & Label & Manifest meaning & Latent meaning \\
\hline 1. Who? & $\begin{array}{l}\text { Students who express } \\
\text { emotions using English words } \\
\text { on desks and on walls }\end{array}$ & & \\
\hline 2. Whom? & $\begin{array}{l}\text { The target person and the } \\
\text { rest of students who will read } \\
\text { these words or expressions } \\
\text { on walls and on desks }\end{array}$ & & \\
\hline 3. Why? & $\begin{array}{l}\text { The reason behind } \\
\text { writing English words to } \\
\text { express emotions on } \\
\text { desks and on walls }\end{array}$ & $\begin{array}{l}\text { Students who wrote } \\
\text { such words find } \\
\text { English language } \\
\text { more prestigious } \\
\text { and superior to } \\
\text { Arabic so it is a matter } \\
\text { of showing off }\end{array}$ & $\begin{array}{l}\text { It is way to hide identities } \\
\text { due to social constraints } \\
\text { and students whose } \\
\text { socialization was based on } \\
\text { fear to express opinions. } \\
\text { So, it is an opportunity to } \\
\text { express emotions freely } \\
\text { but hiding their identity }\end{array}$ \\
\hline
\end{tabular}


"Maybe this because there are many students who hide their identities and they can't express their emotions freely and this due to social reasons like the socialization they go through which is based on fear to express opinions... I think that writing English words on desks is an opportunity for them to feel free without revealing their identity."

The students' answers really were surprising as these teenagers proved to be able to discover the manifest and the latent meanings of this phenomenon (writing emotional words on desks and on walls). It is true that using English words by students to express their emotions proves that students have a positive representation of English as it became a tool to express feelings, to show off and due to social constraints, it became a tool to hide identity.

To conclude, we can confirm that peer group has a positive impact on students' representation of English. These representations are manifested in the way peers exchange attitudes emphasizing a new emerging status of English which is not only a medium of communication but it is also a sign of prestige and showing off between peers.

\subsubsection{The Impact of School on Shaping Students' Representation of English}

The school is society's formal institution where learning takes place. In this part of the research, we will examine the school as a microsystem in which children develop cognitive skills and new ideas. The school's function as socializing agent that provides the intellectual with social experiences, the skills, knowledge, interests and attitudes that characterize them as individuals (Berns, 2010: p. 197). Our focus in this research will target the impact of school as a socializing agent on shaping students' representations and attitudes towards English.

Bir Ali Prep School, for instance, welcomes about 700 students per year. These students come from different places and we may classify these places in two main categories: the rural area and the urban area. Students from different social backgrounds spend between 4 and 6 hours per day at school and they take 3 English sessions per week. In this study, we will examine how school shapes students' representations of English using the participant observation as a research instrument of data collection. We used the following observation grid to examine the impact of school on shaping students' representation of English (Table 7).

Table 7. Observation grid of the teacher.

\begin{tabular}{|c|c|}
\hline Data type & Description \\
\hline 1. Observation notes & Written records of what the observer saw. \\
\hline 2. Casual conversation/informal interviews & Actual conversation with students in class. \\
\hline 3. Semi structured interviews & $\begin{array}{l}\text { Conducting guided interviews } \\
\text { and focus group interview. }\end{array}$ \\
\hline 4. Process flow & Visual or verbal records of common processes. \\
\hline
\end{tabular}




\section{1) The influence of the ecology of teaching on students' representation of} English.

Teachers' impact on socialization and success in motivating students learning is explained by the classic research of Bandura and Walters on modeling "Models who are rewarding, prestigeful, or competent, who possess high status, and who have control over rewarding resources are more readily imitated than are models who lack these qualities" (Bandura \& Walters, 1963: p. 107).

Nobody can deny the importance of teachers and their ways of teaching in shaping students' personalities and attitudes towards knowledge.

As far as English is concerned, English teachers in Bir Ali Prep School developed a democratic style with students because of their ongoing and updated training. This democratic style resulted in contented, cooperative and productive group (Lewin et al., 1939) who developed a positive representation of English though students' results in English are below teachers' expectations.

The participant observation technique resulted in the following findings:

- The observation notes of what the observer saw prove that students show high motivation to study and learn English. $7^{\text {th }}$ form students refuse to take a break and they soon line up in front of the classroom and wait for the English teacher to come. They also show sadness when the teacher tells them that he or she would be absent for some days. Moreover, $7^{\text {th }}$ form students take one-hour group session but they sometimes ask the teacher to allow them spend two hours taking English class.

- The casual conversations and the informal interviews that the observer conducted during 11 years of teaching show that students' best teachers are the English teachers. The $7^{\text {th }}$ form students study a lesson entitled "Who is your favorite teacher?" (Let's learn English) and when I ask students about their favorite subjects and teachers, almost all students mention English as their favorite subject and they mention an English teacher's name as their favorite teacher. And to justify their answer they used adjectives such as "cheerful", "kind" and "helpfup".

However, when I asked them about the other subjects and the other teachers, students reacted unpleasantly naming some teachers who still use the authoritarian style (see Chart 1) in which the teacher directs students. This style resulted in a discontented and hostile group.

Thus, teaching models and styles have a great impact on students' relationship to knowledge and on students' representation of English as a subject.

- To respond to a question about their representation of English teaching in the guided interviews, all students agreed on that teachers and their teaching styles motivate students to learn a particular subject. As far as English is concerned, students answered "Yes" that English teachers and via their teaching styles can motivate students to learn and acquire English. These students also agreed on that teachers should resort to updated techniques such as "songs" "role plays" and "own ongoing encouragement" to tease their motivation and curiosity to learn more English and acquire it as foreign lan- 
guage.

- The process flow that includes visual and verbal records of common processes resulted in the following finding: I have taught almost $1500 \mathrm{stu}$ dents since 2007. Regardless of their different socioeconomic backgrounds, these students developed the same perceptions and attitudes toward English because English teachers developed specific teaching styles which seemed queer to other colleagues. In fact, I and my colleagues always bring realia, laptops and data shows to help students learn English better. By consequence students have shown enthusiasm and they have revealed their motivation to acquire English as a foreign language. In fact, many students attended English clubs and enacted many role plays in English. They also wrote and performed English songs. These data clearly justify that students in Bir Ali prep school developed a positive representation of English as a foreign language even those who are low achievers.

To conclude, we can say that the ecology of teaching English in Bir Ali prep school stands as a positive reinforcing agent that positively shaped students' representations of EFL.

2) The impact of the curriculum on shaping students' representation of English.

The primary purpose of education from society's perspective is the transmission of the cultural heritage: the accumulated knowledge, values, beliefs, and customs of the society (Berns, 2010: p. 197). To transmit this knowledge and beliefs, the state designs a particular curriculum that apparently meets the students' needs. In this part of the research, we will discuss English teachers' opinions about the curriculum as well as students. First, we conducted semi-structured interviews with English teachers in Bir Ali prep school which resulted in the following findings:

The six English teachers that I interviewed expressed their dissatisfaction with the textbooks and the curriculum for they don't meet the students' requirement and needs. They also agreed that some lessons shouldn't be taught because of their "inadequate" cultural content. $9^{\text {th }}$ form students book contains a text dealing with a teenage girl who decided to break the family rules and sneak out. Teachers think that this behavior encourages students to do the same.

As far as the $8^{\text {th }}$ form curriculum, teachers agreed that it is "culturally overloaded'. Students should learn the English table manners, the British customs and their feasts. Meanwhile, my colleagues agreed that the $7^{\text {th }}$ form curriculum is " $O K$ " and it "meets students' needs". According to them, the students' low achievement and their humble performance in English is "The outcome of the textbooks and the curriculum precisely those of $8^{\text {th }}$ and $9^{\text {th }}$ formers". In contrast, students responded differently to a question about their satisfaction with the curriculum. The following chart shows the rate of Bir Ali prep school students' satisfaction with the curriculum.

Chart 3 clearly shows that only $17 \%$ of students are dissatisfied with the school curriculum however $47 \%$ of them are satisfied and $36 \%$ are very satisfied 
with it. These rates confirm that students in Bir Ali are satisfied with the curriculum.

Now, let's examine the statistics in terms of each level.

Bar Chart 1 shows that a very high rate of students expressed their satisfaction with the curriculum. However, $0 \%$ of $7^{\text {th }}$ form students answered that they are dissatisfied with the curriculum. We also notice that a considerable percentage of $7^{\text {th }}$ formers (about $26 \%$ of the whole sample) answered that they are very satisfied with the curriculum. However, these rates change with $8^{\text {th }}$ and $9^{\text {th }}$ formers.

Are you satisfied with the curriculum?
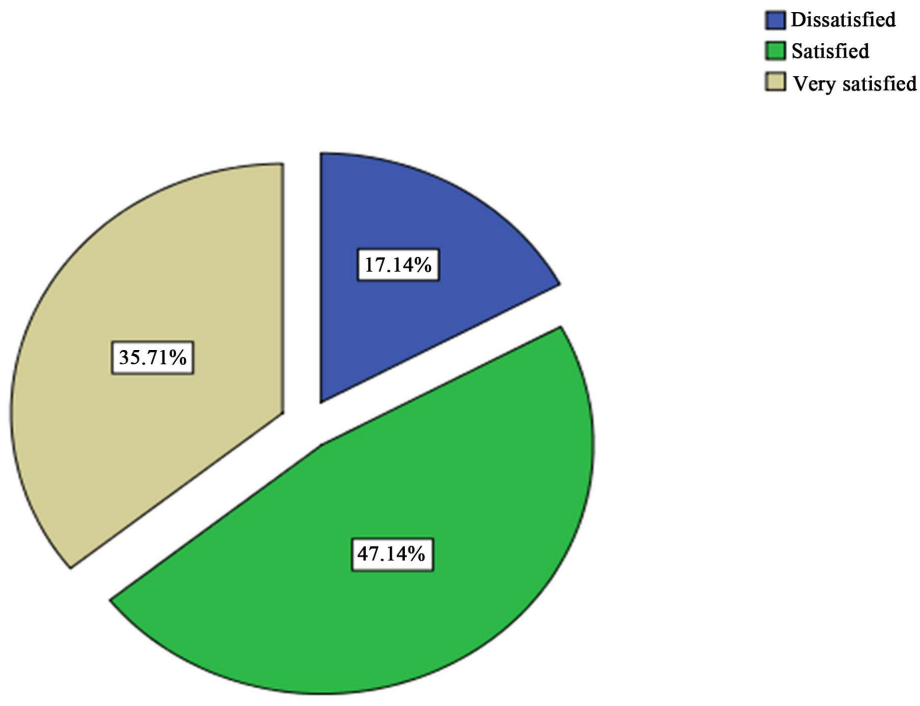

Chart 3. Degree of students' satisfaction with the curriculum.

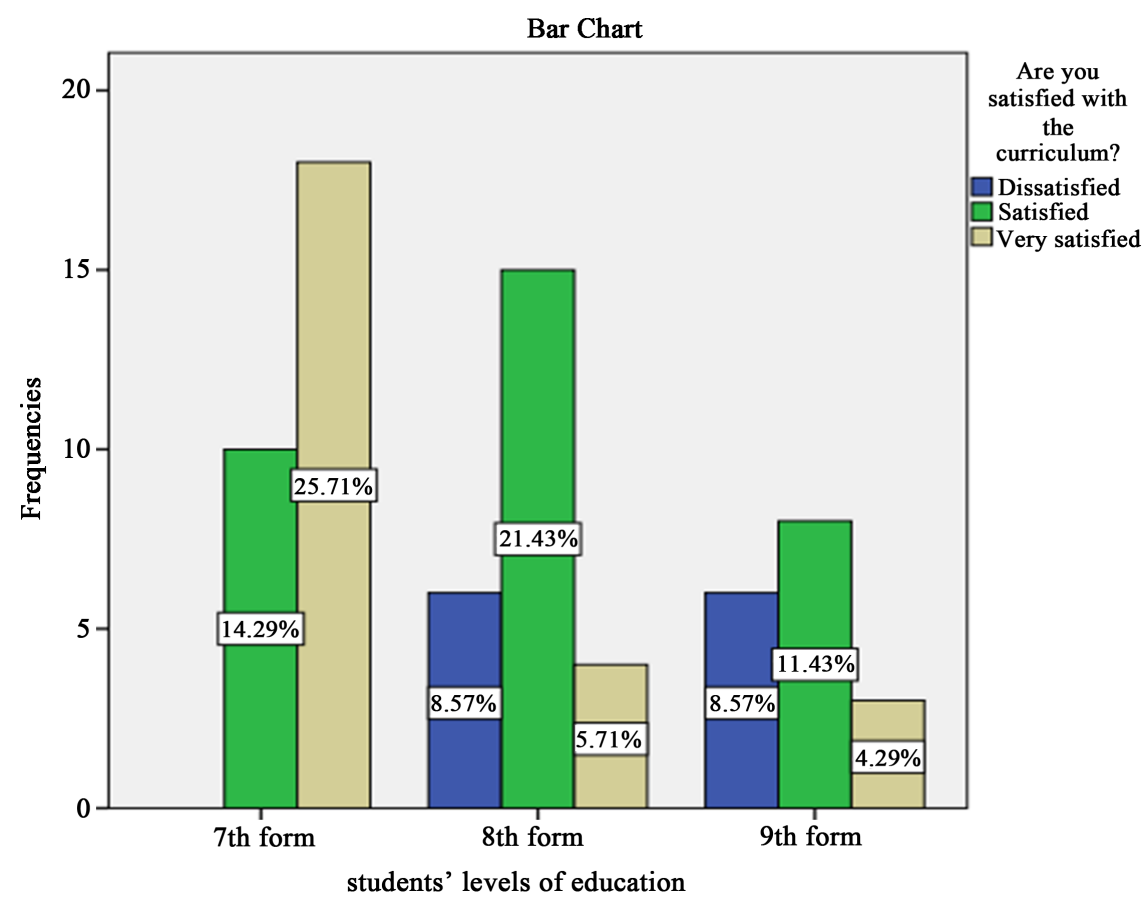

Bar Chart 1. Rate of student's degree of satisfaction with the curriculum in terms of level. 
In fact, $17 \%$ of both levels expressed their dissatisfaction with the curriculum. But still the majority of students (83\%) are either satisfied or very satisfied with the English program. Added to that, we also investigated on if there is a significant correlation between the way students represent and evaluate the English program at school and their level of education. We asked students to answer if the English program meets their needs and objectives or not.

Table 8 reveals the chi-square test of Pearson results which manifests an asymptotic signification of 0.024 which strongly confirms that there a significant correlation between students' level of education and they represent the English program. So, it is legitimate to state that the curriculum positively motivates Bir Ali prep school students to learn English. By consequence, the school curriculum has a positive impact on shaping students' representation of English.

\subsubsection{The Impact of Social Media on Shaping Students' Representation of English}

Carr and Hayes (2015) define social media as "Internet-based channels that allow users to opportunistically interact and selectively self-present, either in real-time or asynchronously, with both broad and narrow audiences who derive value from user-generated content and the perception of interaction with others" (p. 50).

Our investigation will target the impact of Facebook and Youtube on shaping students' representation of English. In fact, 75\% of Bir Ali prep school students use Facebook on a daily basis. This reality reflects these students' openness to others and their desire to discover what is going on around them. Our research will focus only on the impact of one computer-mediated tool which is Facebook on shaping students' representation of English.

Let' study the following Table 9.

Table 8. Correlation between students' level of education and the way they evaluate the English program.

\begin{tabular}{cccc}
\hline & Value & Ddl & Asymptoticsignification (bilateral) \\
\hline Chi-square test of Pearson & $7.461^{\mathrm{a}}$ & 2 & 0.024 \\
Number of valid cases & 70 & & \\
\hline
\end{tabular}

Table 9. The means of communication by which students interact using English.

\begin{tabular}{ccccc}
\hline & & Frequencies & Percentage & Valid Percentage \\
\hline \multirow{3}{*}{ Valid } & Via facebook & 33 & 47.1 & 67.3 \\
& Face to face & 16 & 22.9 & 32.7 \\
\multirow{2}{*}{ Missed } & Total & 49 & 70.0 & 100.0 \\
& & 21 & 30.0 & \\
& Total & 70 & 100.0 & \\
\hline
\end{tabular}


Table 9 provides us with statistical data about the frequencies and the rate of the way students use English to communicate with others. About 49 out of 70 students answered "Yes" that they sometimes use English to communicate with others. $67 \%$ of them use Facebook as a medium of communication and just 33\% use face to face communication. And none of the sample communicates in English using phone as medium of communication. These data clearly show that Facebook represents a shelter for students to communicate in English which, in turn, has a great impact on students' attitudes and representations. When I interviewed students about the rationale behind communicating in English via Facebook and messenger, they answered that "Facebook represents a shelter inside which one feels at ease to express oneself". They also added that they tend to make friends from different countries and English seems necessary to enable students communicate with them. In fact, some students contacted me via messenger and ask me to translate some Arabic utterances or expressions into English. They told me that they had "needed these expressions to communicate with other friends from other countries".

Referring back to students' answers to the interview, we can classify their responses in two categories. Table 10 will describe the manifest and the latent meanings of the two categories.

Social media manifested in Facebook, in particular, represent a shelter for students to escape their daily routines and hide behind a screen or a smartphone to discover the virtual world, interact with peers and react to events or posts. Facebook also stands as a medium via which students can make new links and friends from different countries. English is the suitable language that enables them to communicate and interact with others. Therefore, students find themselves obliged to learn and acquire English to develop and enhance their communicative skills.

To conclude, we can confirm that social media (Facebook) have a positive impact on shaping students' representation of English.

\subsection{Correlation between Students' Representations of English and Their Achievement in Class}

It is true that students' achievement affects their representations of English as

Table 10. Students' representations of Facebook.

\begin{tabular}{lll}
\hline \multicolumn{1}{c}{ Categories } & \multicolumn{1}{c}{ Manifest meaning } & \multicolumn{1}{c}{ Latent meaning } \\
\hline $\begin{array}{l}\text { 1. Facebook as a } \\
\text { refuge }\end{array}$ & $\begin{array}{l}\text { For students, Facebook stands } \\
\text { as a medium through which } \\
\text { they flee the daily routines } \\
\text { and construct a virtual world. }\end{array}$ & $\begin{array}{l}\text { Students try to build new identities } \\
\text { and get recognized in this virtual world. } \\
\text { Many of them try to hide their true } \\
\text { identities using nicknames or } \\
\text { fake names to shape new identities. }\end{array}$ \\
$\begin{array}{l}\text { 2. Medium of } \\
\text { communication } \\
\text { with other friends }\end{array}$ & $\begin{array}{l}\text { English became a compulsory medium } \\
\text { that enables students shape new identities } \\
\text { (cosmopolite citizens) and get recognized }\end{array}$ \\
& $\begin{array}{l}\text { in the sphere of this new world. A world } \\
\text { that destroyed all boundaries. }\end{array}$ \\
\hline
\end{tabular}


a foreign language and vice versa. However, our research paper ended up with the following results.

The bar charts (Bar Chart 2) measure the correlation between students' averages in English and their representations of English as a foreign language.

Bar Chart 2 clearly shows that regardless of students' achievement in English, they still believe that English is not a mere subject at school but it is an international language that helps them find jobs in the future. In fact, we notice that only $16 \%$ of the sample believes that English is a mere subject at school. However, $62 \%$ of the whole sample thinks that English is an international language that helps students find jobs in the future. Thus, microsystems have positively oriented students' representations of English towards a universal perspective which believes that English is an international medium by which people can get integrated in the international labor market.

\section{Discussion}

This work analyzed the impact of Microsystems process on shaping students' representations of EFL. The main issue of the study under scrutiny consists of two main variables relationships. The independent variable which is the microsystems including the family, the school, the peer groups and media have a direct impact on the second dependent variable which is the students' representations of English. Microsystems represent the immediate environment that students contact and interact. Thus, our research emphasized the direct influence of microsystems on students' representations of English as a foreign language. The family still has a considerable role in kids' socialization in Bir Ali. As far as families' representations of school are concerned, many factors contributed to shifting their attitudes towards school. Economy and local culture as well started

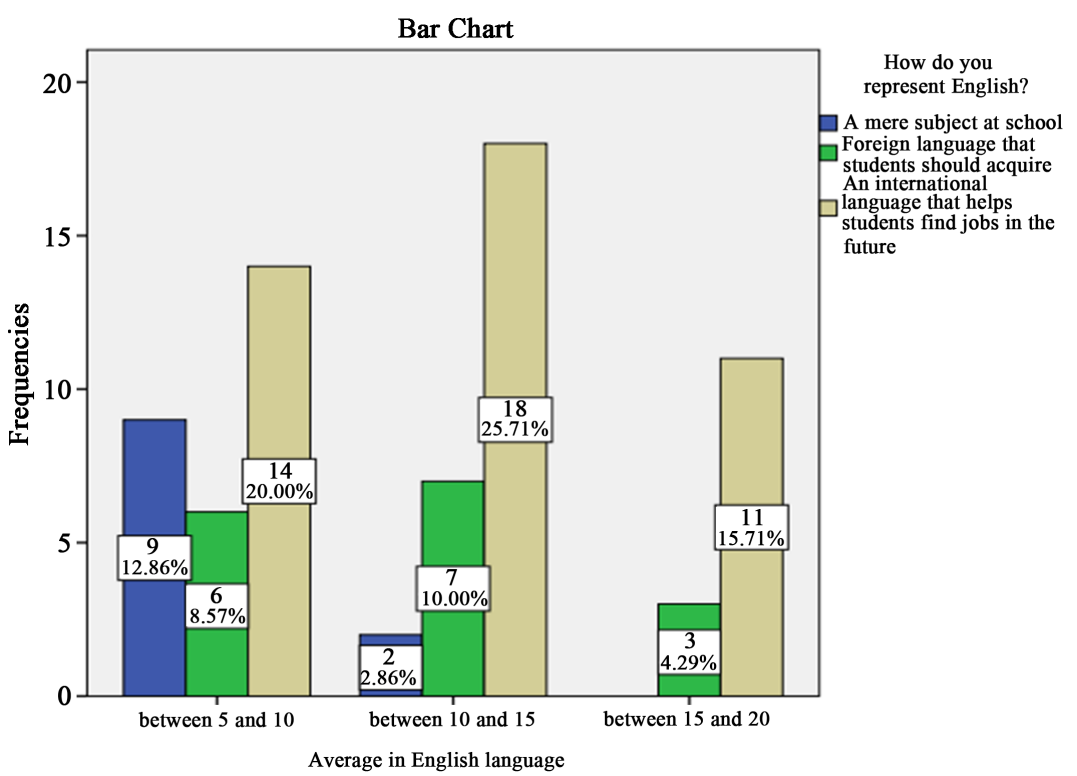

Bar Chart 2. Correlation between students' achievement in English and their representations of it. 
shaping a negative representation of school as it no longer serves as a social ladder. But concerning EFL, families dwelling in rural or urban areas developed positive representations of English as a facilitator for students to guarantee a good job in the future regardless of their performance at school. Thus, the family as a microsystem represents an influential reference group that affects students' representations of English. Thus, the family represents an environmental stimulus that shapes students' responses to ideas and by consequence the family stands as a quasi-physical environment that bombards students with ideas and representations that students can't escape their influence.

Then, no one can deny the importance of school as an important socializing agent. In fact, it tries to construct the new generations' identities and beliefs. The school staff, the curriculum and the schedule contribute to shaping students' behavior at school as well as outside. Concerning English as a subject at school, English teachers try their best to apply the newest methodological tools to improve students' acquisition of English. However, students' results in English are below expectation and this is the outcome of the negative students' relationship to knowledge and to the way teachers design tests. Many students show motivation to learn English in class. They tend to participate in class and answer the teachers' questions. They also show enthusiasm and happiness when they attend the English class. But on the day of the test, students find themselves lost and unable to answer the test questions. As a result, the students' performance in English is below expectations. Despite this fact, Students still have positive representation of English because of teachers' strategies and methods applied in class. So, school as an immediate environment pushes students to acquire English and it partially managed to achieve this goal. On one hand, students developed positive representations of English believing that it is an important language. On the other hand, the majority of students failed to get good marks in English.

Moreover, the influence of peers group on kids' socialization is getting greater and greater. Bir Ali prep school students can't escape this influence which resulted in a negative representation of school and a pragmatic relationship to knowledge (Bouzayani \& Jlassi, 2020). However, the impact of peers group on students' representations of English as a foreign language proved to be positive.

In fact, peers get into a give-and-take process in which students exchange influence, interinfluence and counterinfluence. As far as English is concerned, many details such as imitation, prestige and sense of superiority contribute to shaping a positive representation of English as a foreign language. Peers exert a powerful push that encourages students to acquire English and by consequence they become able to communicate or just utter words or expression in English.

Finally, the fast-widespread technology and ICT (Facebook, Youtube, Satellites, etc...) nullified any culture resistance from the part of students. Most of my students, for instance, believe that the American culture is superior to theirs. Their beliefs are the outcome of the excessive influence of watching English 
movies, English songs broadcast via youtube. Social media, thus, became a considerable socializing agent that shapes students' attitudes, beliefs and representations. Therefore, English as a tool of communication that conveys manifest and latent messages managed to engrave ideas, attitudes and representations in students' minds. As a result, students have developed positive representations of English as a language and as a culture as well.

The results discussed earlier can't be fruitful without crossing them with the two supporting theories that we started with. In fact, Urie Bronfenbrenner developed his ecological systems theory claiming that microsystems (Family, School, Peer group and media) are "patterns of activities and social roles and interpersonal relations experienced by the developing person in a given face-to-face setting with particular physical, social and symbolic features that permit engagement in a sustained, progressively more complex interaction with the immediate environment". The results found in this research paper totally confirm Bronfenbrenner's theory on microsystems.

We can also confirm that Moscovici's theory on social representations proved to be adequate to our research. In fact, Serge Moscovici confirmed that representations are "prescriptive and they impose themselves upon us with an irresistible force. This force is a combination of a structure which is present before we have even begun to think and of a tradition which decrees what we should think (Moscovici, 2018: p. 9). Thus the idea that English is an important language that helps people communicate easily with the world and it also helps students guarantee jobs in the future is present before students come to life and it circulated among adults and families to become a tradition that exerts power on students to shape positive representations of EFL.

Lastly, we can confirm that this study investigated on the way microsystems shaped Bir Ali students' positive representations of EFL. This result can be crossed with that of Cano (2015). Her research resulted in finding that young learners (aged 7 and 8) in Catalonia do not show dislike towards languages. However, our study differs from her research in terms of the methodology approach. She didn't use the quantitative method to exactly measure the reasons behind young learner's attitudes towards languages. Moreover, Meneses \& Bello (2017) noted that social representations and ideologies do not have a direct impact on English and on its linguistic components but they are closely related to political, economic, social and historical reasons that construct the background of English as a second language. I agree to some extent to this approach claiming that macrosystems (politics, economy, society, history) have an impact on constructing the background of English but I disagree with the claim that representations do not have an impact on the linguistic component of English in Chile. In fact, our study confirmed that microsystems and more precisely media push students to speak fluent English as a sign of prestige and showing off. Thus, we can notice that students' attitudes to English differ from one culture to another. 


\section{Conclusion}

This study highlights the effect of Microsystems on shaping students' representations of EFL. Microsystems, which represent the immediate environment that helps students, develop ideas and representations of things, managed to position itself as an influential power that orients students' representations of English. Students, in fact, developed interactions with their physical and quasi-physical environment which in return exerted an influential power to engrave on students' minds the idea that English is an important language that enables them to get integrated into the international society and in the international labor market as well. The quantitative and the qualitative data gathered in this research have proven that the family, the school, peer groups and media have shaped positive students' representations of English as a foreign language. As a result, the majority of students strongly believe that English is no longer just a mere subject at school but it is a means of communication that helps them guarantee jobs in the future. However, though this strong belief in the efficiency and the importance of English as a foreign language, students still suffer low achievement in this subject at school. This reality could be an interesting area of investigation for future research papers.

\section{Conflicts of Interest}

The authors declare no conflicts of interest regarding the publication of this paper.

\section{References}

Bandura, A., \& Walters, R. H. (1963). Social Learning and Personality Development (p. 107). New York: Holt, Rinehart and Winston.

Berns, R. M. (2010). Child, Family, School, Community, Socialization and Support (8th ed., p. 197). Wadsworth, OH: Cengage Learning, Belmont USA.

Bouzayani, N. (2018). The Impact of Macro, Micro and Mesosystems on Shaping Students' Representation of School. International Conference at the Faculty of Arts and Humanities of Sfax.

Bouzayani, N., \& Jlassi, A. (2020). School-Child-Family Linkage and Its Impact on Students' Behavior at School and on Their Relationship to Knowledge: Case Study of Tyna Secondary School in Sfax, Tunisia. Middle East Journal for Scientific Publishing, 3, 106-134.

Bronfenbrenner, U. (1994). Ecological Models of Human Development. In International Encyclopedia of Education (Vol. 3, 2nd ed.). Oxford: Elsevier.

Cano, S. S. (2015). Social Representation of Languages among Primary Education Pupils in Catalonia. Bachelor Thesis. https://ddd.uab.cat/record/140577

Carr, C. T., \& Hayes, R. A. (2015). Social Media: Defining, Developing, and Divining. Atlantic Journal of Communication, 23, 46-65. https://doi.org/10.1080/15456870.2015.972282

Lewin, K., Lippitt, R., \& White, R. K. (1939). Patterns of Aggressive Behavior in Experimentally Created Social Climates. Journal of Social Psychology, 10, 271-301.

https://doi.org/10.1080/00224545.1939.9713366 
Meneses, A. D., \& Bello, C. H. (2017). Students' and Teachers' Social Representations about the RP English Accent and Their Relationship with the Notion of "Native Speaker" in the University Educational Level in Chile. Thesis.

https://www.researchgate.net/publication/330369542

Moscovici, S. (2018). The Phenomenon of Social Representations. In R. Farr, \& S. Moscovici (Eds.), Social Representations (pp. 3-69). Cambridge: Cambridge University Press.

Moscovici, S. (2001). Social Representation: Explorations in Social Psychology. New York: New York University Press Washington Square.

Thomson, M. G., Cohen, L. J., \& Grace, C. O. (2002). Best Friends, Worst Enemies: Understanding the Social Lives of Children. New York: Ballantine Books. 